\title{
A REVIEW ON INDIAN SAGO STARCH AND ITS PHARMACUETICAL APPLICATIONS
}

\author{
Renu Yadav*, Garima Garg
}

\begin{abstract}
Indian sago starch extracted from Tapioca roots finds its application not only as a food but also numerous commercial applications. In the present review we are discussing concisely the extraction, physiochemical properties, chemical modifications and pharmaceutical applications of Indian sago starch. The sago starch is a cheap, easily available, biodegradable and a versatile polymer. Starch has always been an important excipient in the pharmaceutical industry. It is conventionally used as a binder, disintegrant, diluent, granulating agent. It is also a starting material for many other chemicals like ethanol, glucose and cyclodextrin. Several modifications were attempted on native starch to improve and modulate its physiochemical properties.
\end{abstract}

Keywords: Sago starch, tapioca, cyclodextrin, artificial skin, edible film.

\section{Introduction}

Indian sago starch is extracted from Manihot esculenta belonging to family Euphorblaceace. It is also known as SAGO (SABUDANA in Hindi or JAVVARISHI in Tamil). This sago is native to Brazil, Amazon, Colombia, Venezuela, West Indies, Cuba, and Puerto Rico. In India it was introduced in later part of $19^{\text {th }}$ century. Kerala, Andhra Pradesh and Tamil Nadu are the major producers of sago starch [1].

Tapioca root is the basic raw material for sago and starch. These roots contain about $5-13 \%$ starch content, $60-70 \%$ moisture content, $7-12 \%$ protein (32-35\% total carbohydrates) and fat present in trace amount. The high quantity of moisture and starch results in making the roots perishable. Therefore, the processing should incorporate methods for preservation, improving palatability and should also concentrate on the method to reduce the cynogenic toxicity [1].

Indian Tapioca roots are known to have $30-35 \%$ starch with appreciable amount of calcium and vitamin-C [1].

Correspondence to author:

*Renu Yadav

Department of pharmaceutical technology,

Meerut Institute of Engineering and Technology,

$\mathrm{NH}-58$, Baghpat Bypass Road

Meerut (U.P.) India - 25005

Email: renuyadav.1321@gmail.com 


\section{Production (extraction and isolation)}

The extraction and isolation of sago consist of step by step procedure starting from washing of Tapioca roots to presenting them into shiny pearls. The major steps are discussed below:

1) The Tapioca roots are collected and sliced in suitable sizes and the sliced roots are subjected to a thorough washing.

2) The washed roots are peeled, the outer skin is removed.

3) The peeled roots are subjected to crushing by moving them between the rollers. The pulp is obtained.

4) Pulp obtained is sent to the shifter for separating the course particles and the fine ones.

5) Course particles are again made to pass through the roller to make them fine.

6) The milk obtained is allowed to settle down starch particles for 3-8 hours in the settling tank. Here the non-starch part separates from the starch part.

7) From the settling tank, the settled starch is partially dried.The dried cake is crushed down and is sent for further processing such as granulation, roasting and solar drying.

8) Finally it is marketed as shiny as sabu pearls [2].

\section{Physiochemical properties}

With the scanning electron electroscopy, the average size of granules is measured about 16.4 to $30 \mu \mathrm{m}$ and the granules possess an oval shape [3,4]. Amylose contents vary in the range of 24 to $31 \%$. The molecular weight of amylose varies between $1.41 \times 106$ to $2.23 \times 106$ while the molecular weight of amylopectin ranges between $6.70 \times 106$ to $9.23 \times 106$. Intrinsic viscosity of amylose and amylopectin is between $310-460 \mathrm{ml} / \mathrm{g}$ and $210-250 \mathrm{ml} / \mathrm{g}$ respectively. In X-diffraction studies sago starch shows a C-type diffraction pattern [3]. Sago starch has high breakdown temp and low viscosity. Sago possesses a good pasting quality. The swelling capacity of sago starch is greater than other starches because of its larger granule size [5, 6]. Other aspects of physiochemical properties are discussed in table 1 [7].

\section{Chemical modification in sago starch}

1. Effect of galactomannans on thermal and reological properties of sago starch Addition of galactomannans to sago starch in a concentration of $(<1 \%)$ results in a slight increase in gelatinization temperature ( upto $0.6^{\circ} \mathrm{C}$ ). When low molecular mass galactomannans used the storage modules $G^{\prime}$, remains constant or decreases and tan $\delta$ also remains very low ( $0.01-0.03$ at $1.1 \mathrm{hz})$, indicating strong elastic gels. Galactomannans at (1\%) concentration results in tan $\delta$ between 0.20 at $0.1 \mathrm{~Hz}$, which indicates decrease in elastic characteristic. Presence of galactomannans significantly improves the freeze-thaw stability [8].

\section{Effect of cellulose addition on hydrolysis of sago starch}

In the initial stage of hydrolyzation process of sago starch granules, addition of cellulose results in an increase in the ability of raw starch digesting amylase for digesting the sago starch granules [9]. 


\section{Gelatinisation of sago starch with sugar and salts}

With low level of water and high level of sucrose, the gelatinisation temperature increases whereas gelatinisation enthalpy remains unaffected. Shape of the gelatinisation endotherm also changes with addition of sucrose. The double endotherm obtained in low-level of water-starch system changes in single endotherm with sucrose. Sample having a starch-water ratio of $2: 3$ and $3: 2$ in $\mathrm{NaCl}$ concentration of 1 to $5 \mathrm{M}$, the gelatinisation temperature of sago increase and then decreased with an increase in $\mathrm{NaCl}$ concentration. $\mathrm{NaCl}$ creates the similar effect on endotherm as that of sucrose, when studied under differential scanning colorimetry (DSC) $[10,11,12]$.

\section{Effect of temperature and solute concentration on viscosity}

Viscosity is measured with ubbeholde capillary. With increase in temperature the intrinsic viscosity decreases but critical concentration remains constant over range of temperature. With the presence of sodium chloride, the intrinsic viscosity increases and decreases with the presence of sugar in sago starch. Sodium chloride enhances the molecular entanglement and lowers the critical concentration [13].

\section{Effect of freezing and thawing techniques}

The stability of sago starch is studied under the influence of freezing and thawing technique. Tapioca starch is freezed with cryogenic quick freezing ( CQF ) method and thawed at $30^{\circ} \mathrm{C}, 60^{\circ} \mathrm{C}$ and $90^{\circ} \mathrm{C}$ respectively in a water bath or in an microwave at boiling temperature for five cycles. No separation of water takes place in any cycle, therefore the percentage of syneresis is zero. Sago starch frozen by CQF technique possesses a lower percentage of syneresis than that frozen at $-18^{\circ} \mathrm{C}$ in every freeze-thaw cycle [14].

\section{Effect of $\mathrm{pH}$ on phosphorylation of sago starch}

At $\mathrm{pH}$ between 6 to 11 , sago starch in semi dry state is phosphorylated with $2 \%$ sodium trimetaphospahte (STMP) , 5\% sodium tripolyphospahte ( STPP) or in combination of both. With STPP, the degree of phosphorylation decreases from 0.186 to $0.033 \% \mathrm{P}$ when reaction $\mathrm{pH}$ increases from 6 to 11 . In case of STPP, the degree of phosphorylation increases from 0.066 to $0.119 \% \mathrm{P}$. When the mixture of STMP and STPP is used, the degree of phosphorylation decreases from 0.320 to $0.115 \%$. This mixture yields the best starch phosphate at $\mathrm{pH} 9.5$, and the paste shows low hot paste viscosity and high cold paste viscosity [15].

\section{Effect of retrogradation on enzyme susceptibilty of sago starch}

Retrogradation studies on gelatinised starch for different times and under various temperature conditions shows that as the retrogadation increases, it reduces the enzyme susceptibility of sago starch and sago products at $37^{\circ} \mathrm{C}[16]$.

\section{Effect of cross linking reagents and hydroxypropylation levels}

Hydroxypropylation of native sago starch with $10-12 \%$ propylene oxide and cross linking with a mixture of $2 \%$ sodium trimetaphosphate (STMP) and $5 \%$ sodium tripolyphosphate ( STPP) produces the modified starch of most desirable properties . The dual modified sago starch has no viscosity breakdown, in addition shows high acid resistance with freeze-thaw stability and improved gel texture [17]. 


\section{Pharmaceutical applications}

\section{Tablet formulation}

Sago starch is used as a binder in the formulation of tablets. It possesses a good binding quality. The tablets formulated with sago starch as binder shows an increase in disintegration time and hardness with a decrease in friability. Apart from being used as a binder it also finds use as a granulating agent and diluent [7].

\section{Starch based hydrogel as artificial skin}

Cross linking of polyvinyl alcohol and starch suspension with glutaraldehyde as cross linking agent, a novel artificial membrane of hydrogel is prepared. The prepared hydrogel protects the injured skin or wound surface by keeping the surface moist as well as absorbing the excaudate leading to speedy recovery. These hydrogels also promotes the tissue repair including growth factor and lysosomes in contact with the wound. Since these hydrogels are prepared from the starch grain therefore possess a high quantity of water which is indeed requirement for keeping the wound moist $[18,19]$.

\section{Antibacterial activity}

Edible films are prepared with partially hydrolysed sago starch and alginate. When these edible films are incorporated with glycerol $(0 \%$ and $20 \mathrm{w} / \mathrm{w})$ and lemongrass oil ( $0.1 \%$ to $0.4 \%$ ), they act as plasticizer and natural antimicrobial agent respectively . This film prepared is effective against Escherichia coli [20].

\section{As packaging material}

Sago esters prepared by pre-treatment of sago starch with excess of formic acid followed by acetylation with acid chloride results in formation of modified sago starch which can overcome the physiochemical problems associated with native starch. This chemically treated sago starch is used as substituent to petroleum based plastic material in packaging industries. Starch base material is preferred over petroleum base material because starch is biodegradable and do not create any disposal problem as presented by petroleum base material [21].

\section{Culture medium}

Sago is used as gelling agent in culture medium. Sago contains small amount of sugars, fibre, protein, calcium as well as other minerals. Generally agar is used as gelling agent in culture medium. The biggest drawback with agar is that it results in total $80 \%$ of production cost. Sago starch is a cheap alternative to agar, also use of sago have shown good results for the plants where it is used [22].

\section{Production of ethanol}

Commercially sago starch is used for production of ethanol with glucomylase and Zymomonas mobilisZM4 using a Box-Wilson central composite design protocol. Sago starch used as substrate for fermentation is cheap and yields high alcohol levels. Zymononas mobilis is grown in medium in which glucoamylase (AMG) is added exogenously which allows simultaneous starch esterification and fermentation (SSF). The SSF process results in hydrolysis of starch and ethanol fermentation 
simultaneously. This process offers an increased rate of hydrolysis, reduced fermentation time and decreased capital investment [23].

\section{Glucose production}

Penicillium brunneum isolated from sago processing site produces amylase which digests the starch granules to glucose. Treatment of sago starch by subjecting to temperature gelatinization temperature at low $\mathrm{pH}$ results in enhanced ability of enzyme to digest sago starch granules [24].

\section{Cyclodextrin production}

Cyclodextrin glycosyltransferase (CGTase) synthesizes cyclodextrin. It is widely used in food, pharmaceutical, agricultural and cosmetic industries. Cyclodextrin is produced by Bacillus circulans CGTase at an optimum temperature and $\mathrm{pH}$ of 55 $60^{\circ} \mathrm{C}$ and 4.5 to 5 respectively [25].

\section{Production of UV curable coatings}

Grafted copolymer of sago starch is prepared by grafting Glycidyl methacrylate (GMA) on sago starch using ceric ammonium nitrate as initiator in aqueous medium. These grafted copolymers of starch are incorporated into UV curable films. This increases the flexibility of the cured films [26, 27, 28].

\section{Conclusion}

The sago starch, because of its availability, easy processing biodegradability and physiochemical properties can be successfully used in pharmaceutical industry. Its application is now not only limited to binder, disintegrant and diluent but it can also be crosslinked and modified for delivering novel drug delivery system and also as a packaging material. Cyclodextrin, a fermentation product from starch has been used not only as a complexing agent but also for solubility enhancement of poorly water soluble drugs. Thus we can conclude that sago starch can be used in place of many synthetic polymers as well as can be alternative of starches from expensive sources. 
TABLE 1: Physicochemical properties of sago starch

\begin{tabular}{|c|l|c|}
\hline S.NO & PROPERTIES & SAGO STARCH \\
\hline 1$)$ & Bulk density $\left(\mathrm{g} / \mathrm{cm}^{3}\right)$ & 0.57142 \\
\hline 2$)$ & Tapped density $\left(\mathrm{g} / \mathrm{cm}^{3}\right)$ & 0.76923 \\
\hline 3$)$ & Angle of repose $\left({ }^{\circ}\right)$ & 32.39 \\
\hline 4$)$ & Carr's index & 25.7513 \\
\hline 5$)$ & Paste clarity (\%) & 8.47 \\
\hline 6$)$ & \% solubility & 0.56 \\
\hline 7$)$ & Yield stress (pascal) & 57.493 \\
\hline 8$)$ & Viscosity (pascal) & 34.16 \\
\hline 9$)$ & Swelling power & 26.10 \\
\hline 10$)$ & $\%$ loss on drying & 2.2 \\
\hline 11$)$ & Diameter of the starch grain & $16.4-30$ \\
\hline 12$)$ & Temperature $\left({ }^{\circ} \mathrm{C}\right)$ & $2-5$ \\
\hline 13$)$ & Gelatinisation & $68-73$ \\
\hline 14$)$ & Total microbial load & PASS \\
\hline 15$)$ & Limit test (chloride) & PASS \\
\hline & & \\
\hline
\end{tabular}

\section{References:}

[1] Sabuindia, http://www.sabuindia.com/sago1.htm (13 April 2013)

[2] Sabuindia, http://www.sabuindia.com/sago2.htm (13 April 2013)

[3] Ahmad FB, Williams PA, Doublier JL, Durand S, Buleon A. (1999) Physico-chemical characterisation of sago starch. Carbohydrate Polymer, 38(4), 361-370.

[4] Yiu PH, Loh SL, Rajan A, Wong SC, Bong CFJ. (2008) Physiochemical Properties of Sago Starch Modified by Acid Treatment in Alcohol. American Journal of Applied Sciences, 5 (4), 307-311.

[5] Wattanachant S, Muhammad SKS, Mat Hashim D, Rahman, RA. (2002) Suitability of sago starch as a base for dual-modification. Songklanakarin Journal of Science and. Technology, 24(3), 431-438.

[6] Ahmad FB, Williams PA. (1998) Reological properties of sago starch. Journal of agricultural and food chemistry, 46(10), 4060-4065. 
[7] Gangwar S, Singh S, Garg G, Pawar, Sharma PK. (2010) Isolation and evaluation of binding property of sago starch in paracetamol tablet. International journal of pharmaceutical research and development, 2(1).

[8] Ahmad FB, Williams PA. (2001) Effect of Galactomannans on the Thermal and Rheological Properties of Sago Starch. Journal of Agricultural and Food Chemistry, 49(3), 1578-1586.

[9] Haska N, Ohta Y, (1993) Effect of Cellulase Addition on Hydrolysis of Sago Starch Granules by Raw Starch Digesting Amylase from Penicillium brunneum No. 24. Starch Stärke, 45, 237-241.

[10] Ghani MBA, Man YBC, Ali AB, Hashim DBM. (1999) Differential scanning calorimetry: gelatinisation of sago starch in the presence of sucrose and sodium chloride. Journal of the Science of Food and Agriculture, 79, 2001-2009.

[11 Ahmad FB, Williams PA. (1999) Effect of sugars on the thermal and rheological properties of sago starch. Biopolymers, 50, 401-412.

[12] Ahmad FB, Williams PA. (1997) Effect of Salts on the Gelatinization and Rheological Properties of Sago Starch. Journal of agricultural and food chemistry, 47(8), 3359-3366.

[13] Islam MN, Mohd AMD, Noor MAB. (2001) Effect of Temperature and Starch Concentration on the Intrinsic Viscosity and Critical Concentration of Sago Starch (Metroxylon sagu). Starch - Stärke, 53, 90-94.

[14] Varavinit S, Anuntavuttikul S and Shobsngob S. (2000) Influence of Freezing and Thawing Techniques on Stability of Sago and Tapioca Starch Pastes. Starch - Stärke, 52, 214-217.

[15] Muhammad K, Hussina F, Man YC, Ghazali HM, Kennedy JF. (2000) Effect of pH on phosphorylation of sago starch. Carbohydrate Polymers, 42(1), 85-90.

[16] Cui R, Oates CG. (1997) The effect of retrogradation on enzyme susceptibility of sago starch. Carbohydrate Polymers, 32(1), 65-72.

[17] Wattanachanta S, Muhammad K, Hashim DM, Rahman RA. (2003) Effect of crosslinking reagents and hydroxypropylation levels on dual-modified sago starch properties. Food Chemistry, 80(4), 463-471.

[18] Kunal P, Banthia AK, Majumdar DK. (2006) Starch Based Hydrogel with Potential

Biomedical Application as Artificial Skin, African Journal of Biomedical Research, 9, 23-29.

[19] Hashim K, Dahlan KZM, Bahari K, Yoshii F, Kume T. (2001-05) Development of Sago Starch Hydrogel for Wound Dressing. JAERI-Conf.

[20] Maizura M., Fazilah A, Norziah M, Karim A. (2007) Antibacterial Activity and Mechanical Properties of Partially Hydrolyzed Sago Starch-Alginate Edible Film Containing Lemongrass Oil. Journal of Food Science, 72, C324-C330. 
[21] Dzulkefly K, Koon SY, Kassim A, Sharif A, Abdullah AH. (2007) Chemical modification of sago starch by solventless esterification with fatty acid chlorides. The Malaysian Journal of Analytical Sciences, 11, 395-399.

[22] Naik PS, Sarkar D. (2001) Sago: an alternative cheap gelling agent for potato in vitro culture. Biologia plantarum, 44(2), 293-296.

[23] Ratnam BVV, Rao MN, Rao MD, Rao, Rao SS, Ayyanna C. (2003) Optimization of fermentation conditions for the production of ethanol from sago starch using response surface methodology. World Journal of Microbiology \& Biotechnology, 19, 523-526.

[24] Haska N, Ohta Y. (1991) Glucose Production from Treated Sago Starch Granules by Raw Starch Digesting Amylase from Penicillium brunneum. Starch - Stärke, 43, 102-107.

[25] Charoenlap N, Dharmsthiti S, Sirisansaneeyakul S, Lertsiri S. (2004) Optimization of cyclodextrin production from sago starch. Bioresearch Technology, 92(1), 49-54.

[26] Han TL, Kumar RN, Rozman HD, Noor MAM. (2003) GMA grafted sago starch as a reactive component in ultra violet radiation curable coatings. Carbohydrate Polymers, 54(1), 509-516.

[27] Lutfor MR, Sidik S, Yunus WMZ, Rahman MZA, Mansoor A, Jelas H. (2001) Preparation and swelling of polymeric absorbent containing hydroxamic acid group from polymer grafted sago starch. Carbohydrate Polymers, 45(1), 95-100.

[28] Lutfor MR, Sidik S, Yunus WMZ, Rahman MZA, Mansor A, Haron MJ. (2001), Synthesis and characterization of poly(hydroxamic acid) chelating resin from poly(methyl acrylate)-grafted sago starch. Journal of Applied Polymer Science, 79, 1256-1264. 